\title{
Detection of the Electrical Conductivity and Acidity of Honey from Different Areas of Tepi
}

\author{
Desissa Yadata \\ Mizan Tepi University, Post office box 121, Ethiopia \\ *Corresponding Author: desissayad@yahoo.com
}

Copyright (C 2014 Horizon Research Publishing All rights reserved.

\begin{abstract}
Honey is the ingredient of most industrial products for sweetening and improving its food composition. The study is therefore based on the determination of physical parameters such as electrical conductivity and acidity. The instrumentation and apparatuses used in the work are conductometry and titration apparatuses. Honey samples obtained from different areas with respect to Tepi town have been analyzed and the result obtained is on the basis of conductometry and acidity measurement. Hence $20 \mathrm{~g}$ of each anhydrous honey sample was weighed and dissolved in $100 \mathrm{~mL}$ of deionized water in order to prepare $20 \%(\mathrm{w} / \mathrm{v})$ solution to measure conductivity. The acidity is detected after $10 \mathrm{~g}$ of each honey sample is dissolved in $75 \mathrm{~mL}$ of deionized water. The conductivity in summer honey determined to be $0.097 \mathrm{mS} / \mathrm{cm}, 0.153 \mathrm{mS} / \mathrm{cm} \quad 0.117 \mathrm{mS} / \mathrm{cm}$ and $0.337 \mathrm{mS} / \mathrm{cm}$ in Korcha, Mexi, Sheko and Gobito respectively. Acidity is found to be 17, 28.67, 29 and $25 \mathrm{miliequi} / \mathrm{Kg}$. The conductivity in winter honey is detected to be $0.123,0.186,0.103$ and $0.246 \mathrm{mS} / \mathrm{cm}$. The acidity in winter honey is $3.36-4.26$ and $18.3-25.3 \mathrm{meq} / \mathrm{Kg}$ from $\mathrm{pH}$ meter and titration respectively. The conductivity of darker honey is slightly greater than lighter honey, which indicated that the darker honey has more mineral content; and acidity of three honey samples is almost similar. The honey products are safe and fit the international honey commission standard and probably both darker and lighter honey are nutritionally important.
\end{abstract}

Keywords Acidity, Color, Conductivity, Honey, Nectar

Abstract for the work is summarized as follows
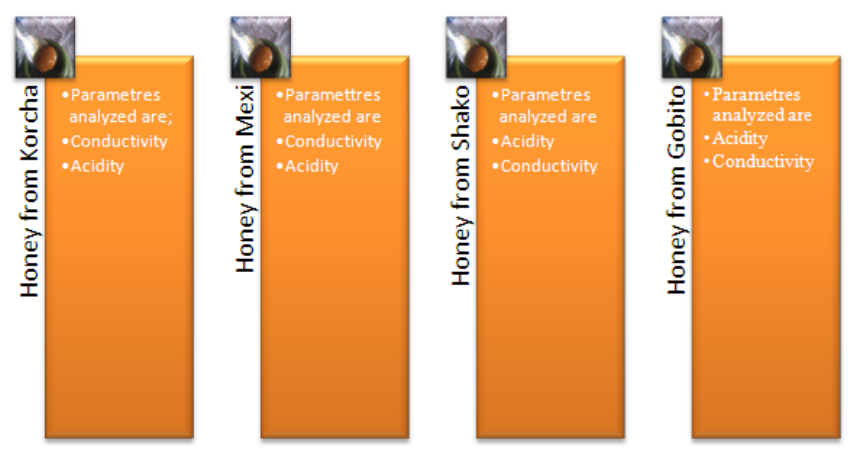

\section{Introduction}

Honey is one of the complex food stuffs produced by nature, and certainly the only sweetening agent that can be used by humans without processing. Both Predisposition and the commercialization probabilities depend on sensory properties (color, flavour and texture). These properties are a complex function of physicochemical parameters, which are over time, determined by the botanic and geographic origins. Therefore, the characterization of honeys is a hard task in response to consumer's demands. The International honey standards allow specific denominations for honey produced from particular nectar [1]. One of the way of handling scientific analyses of various honeys must have three aims: quality control, purity control, and identification of adulterations. Honey quality test is important task to be done in order to measure and evaluate the product manufactured locally as well as commercially. Hence the study makes its attention on the determination of conductivity and acidity of honey collected from products manufactured locally $[1,2]$.

The conductivity is a good criterion of the botanical origin of honey and thus is very often used in routine honey quality control and purity. Honey contains organic acids and mineral salts, compounds which chemically are called "ionizable" that is when in solution, they have the property to conduct electric current. The electrical conductivity of honey is defined as that of a $20 \%(\mathrm{w} / \mathrm{v})$ weight in solution at $20^{\circ} \mathrm{C} \pm 0.5$, where the $20 \%$ refers to anhydrous honey and express in mill Siemens per centimeter $\left(\mathrm{mS}_{\mathrm{cm}} \mathrm{cm}^{-1}\right)[2,3]$.

The acidity in honey is caused by the organic acid usually existing in all honeys (tartaric, citric, oxalic, acetic, etc.) either from nectar or bees' secretions. The acidity of honey can be measured by titration against sodium hydroxide equivalents or direct measurement of $\mathrm{pH}$. The commercial high-quality honey should have the free acidity up to 50 mili equivalents/Kg of honey. Natural acidity of honeys may increase when they grow older, when it is extracted from combs with propolis, and especially when it deteriorates due to fermentation. Moreover, the honey adulterated with sugar syrup has a very low acidity (less than 1 ) while that adulterated with inverted sugar has a clearly higher acidity. According to the National Honey Board, the acidity of honey 
ranges from a $\mathrm{pH}$ of about 3.4 to about 6.1 , with an average of 3.9 [4].

The acidity of any honey is directly related to the floral sources that created it. Honey contains a number of different acids, including about 18 amino acids, many different organic acids, as well as aliphatic and aromatic acids. The aromatic acids greatly contribute to the flavor of honey [5].

International honey commission established standards to evaluate the quality of honey based on the color. Evaluating the quality of honey in terms of the conductivity and acidity has got special attention in this study because acidity and conductivity can affect the importance of honey and to classify honey and its products.

The objective of the study is to determine physical parameters such as electrical conductivity and acidity.

The study is expected to be significant to classify honey on the color variation which is one way of indicating quality and emitted the first kind of scientific research for the area. Hence it benefited the producer and consumer in providing awareness how easily the quality of honey can be governed by testing the color [6].

\section{Materials and Methods}

\section{Instrumentation and chemicals}

Apparatuses and instrumentation used for the study are plastic bottles, thermometer, conductometry, $\mathrm{pH}$ meter, volumetric flasks, beakers, stirrer, graduated cylinder, temperature compensator immersed in solution. Reagents and chemicals used for preparation of sample are deionized water, Analytical Reagent grade Potassium chloride $(\mathrm{KCl})$ dried at $105^{\circ} \mathrm{C}$, Analytical Reagent grade $0.1 \mathrm{MNaOH}$, and phenolphthalein indicator (1g of phenolphthalein dissolved in $95 \%$ ethanol solution) $[6,7]$

\section{Sampling and sample collection}

The first category of honey samples were obtained from four different locations (Korcha, Mexi, Gobito and Shako) with respect to Tepi town and three replicate samples in each case were collected randomly using plastic bottles during summer season. The second phase of sample was obtained from the same area during winter season. The collected samples were preserved in ice bag and transported to the laboratory for investigation.

\section{Sample preparation and analysis}

Sample preparation involves identification and grouping with respect to color, season and place of collection. The honey samples collected are classified as lighter and darker because conductivity and acidity can significantly be affected by color.

$20 \mathrm{~g}$ of each anhydrous honey samples dissolved in $100 \mathrm{~mL}$ of deionized water to prepare $20 \%(\mathrm{w} / \mathrm{v})$ solution for measurement of conductivity. Secondly $10 \mathrm{~g}$ of each sample has been dissolved in $75 \mathrm{~mL}$ of deionized water for the determination of acidity.

Preparation of reagents taken place by dissolving $0.7456 \mathrm{~g}$ of standard potassium chloride in $100 \mathrm{~mL}$ used to calibrate the conductometry and further to measure cell constant. Standardized sodium hydroxide; $0.1 \mathrm{M}$ of $\mathrm{NaOH}$ solution was determined by titrating with known sulfuric acid and $4 \mathrm{~g}$ of the reagent dissolved in $100 \mathrm{~mL}$ deionized water.

\section{Preparation of reagents to determine conductivity}

$40 \mathrm{~mL}$ of $0.1 \mathrm{M}$ potassium chloride solution was added to a beaker and the cell immersed in the solution together with a thermometer. The electrical conductance $(\mathrm{G})$ of this solution has been detected in $\mathrm{mS}$ after the temperature has been equilibrated to $20^{\circ} \mathrm{C}$. Conductivity $(\mathrm{mS} / \mathrm{cm})=$ [cell constant $\left.\left(\mathrm{cm}^{-1}\right)\right]^{*}[$ conductance from the conductometry $(\mathrm{mS})]$

\section{Preparation of reagents to determine acidity}

The acidity of the sample was analyzed and detected by titration; i.e. titratable acids such as tartaric acids, acetic acids and other organic acids are determined by fixing the $\mathrm{pH}$ at about 8.3 which was done to prevent the hydrolysis problem of lactose which can influence the result of the measurement. Acidity of honey from titration expresses in mili equivalents per $\mathrm{Kg}$ of honey samples and calculated as

$$
\operatorname{acidity}\left(\frac{\mathrm{meq}}{\mathrm{kg}}\right)=\frac{\text { volume of } 0.1 \mathrm{MNaOH} \text { consumed } * 10}{\mathrm{Kg} \text { of honey sample }}
$$

Where 10 indicates the dilution factor of honey sample during analysis; the acidity was further determined from $\mathrm{pH}$ measurement which accompanied the calibration of $\mathrm{pH}$ meter at 3, 7and 9 . 
Table 1. The results obtained from different honey samples for acidity and conductivity

\begin{tabular}{|c|c|c|c|}
\hline Sample & Conductivity $(\mathrm{mS} / \mathrm{cm})$ & $\begin{array}{c}\text { Acidity from } \mathrm{pH} \\
\text { measurement }\end{array}$ & Acidity (mili eq $\mathrm{Kg}^{-1}$ ) \\
\hline \multirow{2}{*}{ HG } & Summer $0.0966 \pm 0.0057$ & Summer $4.17 \pm 0.13$ & Summer $17 \pm 2.64$ \\
\hline & Winter $0.123 \pm 0.015$ & Winter $3.36 \pm 0.32$ & Winter $18.3 \pm 0.57$ \\
\hline \multirow{2}{*}{$\mathrm{HM}$} & Summer $0.153 \pm 0.0057$ & Summer $3.96 \pm 0.01$ & Summer $28.67 \pm 1.53$ \\
\hline & Winter $0.186 \pm 0.02$ & Winter $4.1 \pm 0.095$ & Winter $22.3 \pm 1.52$ \\
\hline \multirow{2}{*}{ HS } & Summer $0.117 \pm 0.0152$ & Summer $3.96 \pm 0.01$ & Summer $29 \pm 1$ \\
\hline & Winter $0.103 \pm 0.025$ & Winter $4.26 \pm 0.25$ & Winter $25.3 \pm 2.51$ \\
\hline \multirow[t]{2}{*}{ HK } & Summer $0.337 \pm 0.0152$ & Summer $4.00 \pm 0.01$ & Summer $25 \pm 1$ \\
\hline & Winter $0.246 \pm 0.011$ & Winter $3.73 \pm 0.15$ & Winter $21.3 \pm 1.52$ \\
\hline
\end{tabular}

HG- Honey Gbito, HM- Honey Mexi, HS- Honey Shako, HK- Honey Korcha

\section{Results and Discussion}

Electrical conductivity (EC) was measured according to the harmonized methods of the European honey commission and expressed in $\mathrm{mS} / \mathrm{cm}$. EC was measured at $20 .{ }^{\circ} \mathrm{C}$ using microcomputer conductivity meter. All measurements were performed in triplicate.

\section{Conductivity}

Conductivity is the indication of ionizable acids and compounds in aqueous solution. The conductivity measurement collected from analysis of $40 \mathrm{~mL}$ of different honey samples solution at $20^{\circ} \mathrm{C} \pm 0.5$, from different location with respect to Tepi; is in the range of $0.09-0.1,0.15-0.16$, $0.1-0.13$ and $0.32-0.35 \mathrm{mS} / \mathrm{cm}$ in case of Korcha, Mexi, Shako and Gobito respectively in summer. In winter season $0.11-0.14,0.17-0.21,0.08-0.13$ and $0.24-0.26 \mathrm{mS} / \mathrm{cm}$ in Korcha, Mexi, Shako and Gobito have been determined. The conductivity value from Gobito is greater than in three cases. According to the study conducted the conductivity was found to be less than 1 . The current work compared with the literature conducted before; for instance $0.39-0.89 \mathrm{mS} / \mathrm{cm}$ for willow honey samples, $0.52-0.63 \mathrm{mS} / \mathrm{cm}$ for winter rape and $0.52-0.85 \mathrm{mS} / \mathrm{cm}$ for floral honey samples have been reported [10].

\section{Acidity}

The acidity of honey determined by titration against $0.1 \mathrm{M}$ of $\mathrm{NaOH}$ was reported after conversion of the volume of base consumed by the formula, acidity $\left(\frac{\mathrm{meq}}{\mathrm{Kg}}\right)=$ $\frac{m L \text { of base } * 10}{K g \text { of honey }}$, According to the result in summer honey an average of 17 miliequivalent/Kg in Korcha, 28.66 miliequivalent $/ \mathrm{Kg}$ in Mexi, 29 miliequivalent $/ \mathrm{Kg}$ in Shako and 25 miliequivalent in Gobito have been detected. The acidity is also further tested with $\mathrm{pH}$ meter and the results are all less than 7; i.e.; 3.95 to 4.30 . In Korcha sample 4.18, in Mexi sample 3.96, in Shako sample 3.96 and in Gobito sample 4.00. In winter honey 3.36, 4.1, 4.26 and 3.37 and further $18-28 \mathrm{meq} / \mathrm{Kg}$ have been detected.

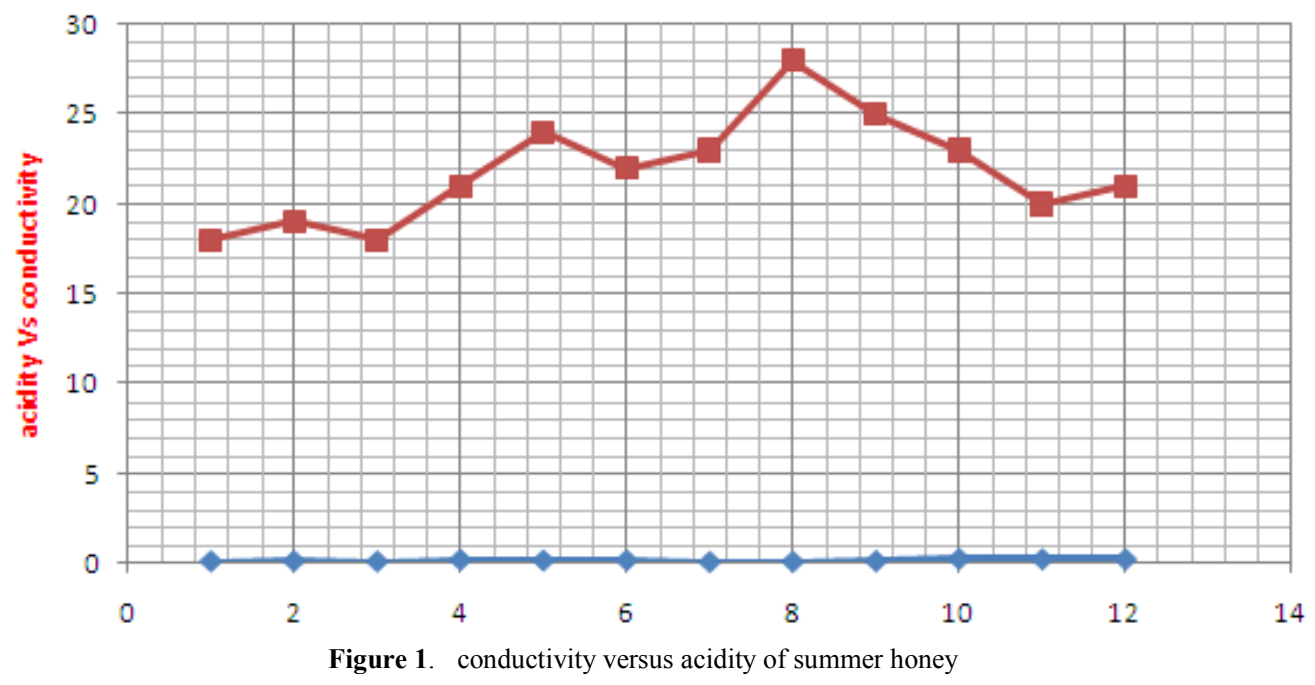




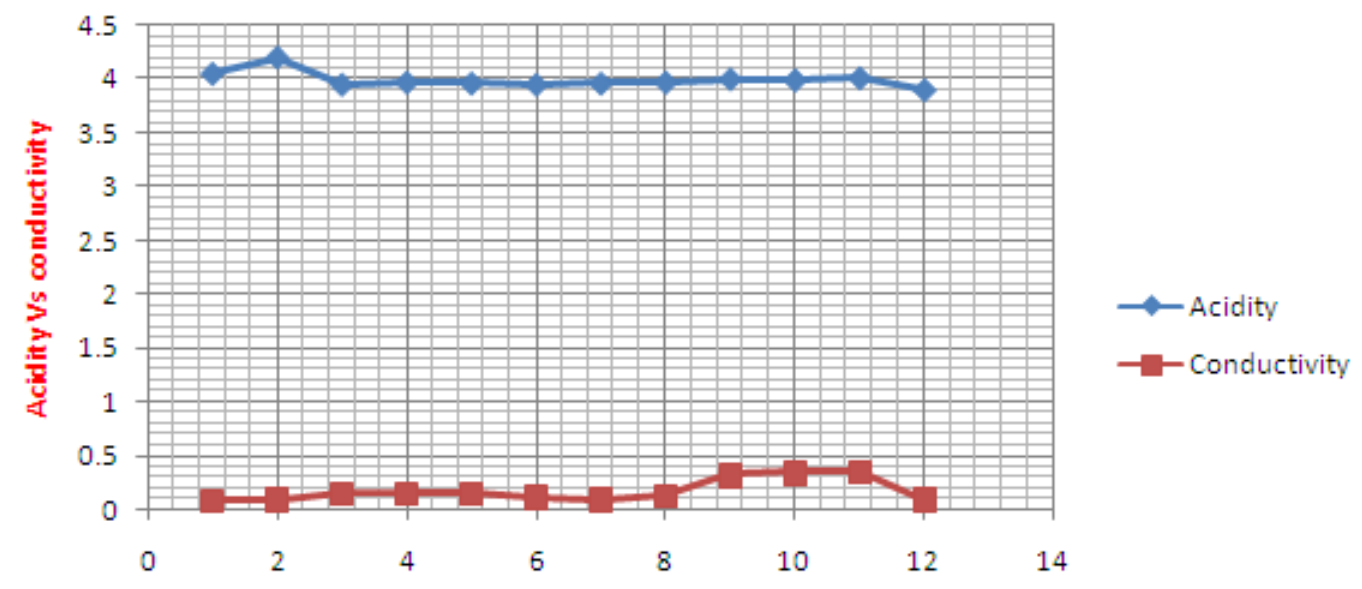

Figure 2. Conductivty $(\mathrm{mS} / \mathrm{cm})$ versus acidity $(\mathrm{pH})$

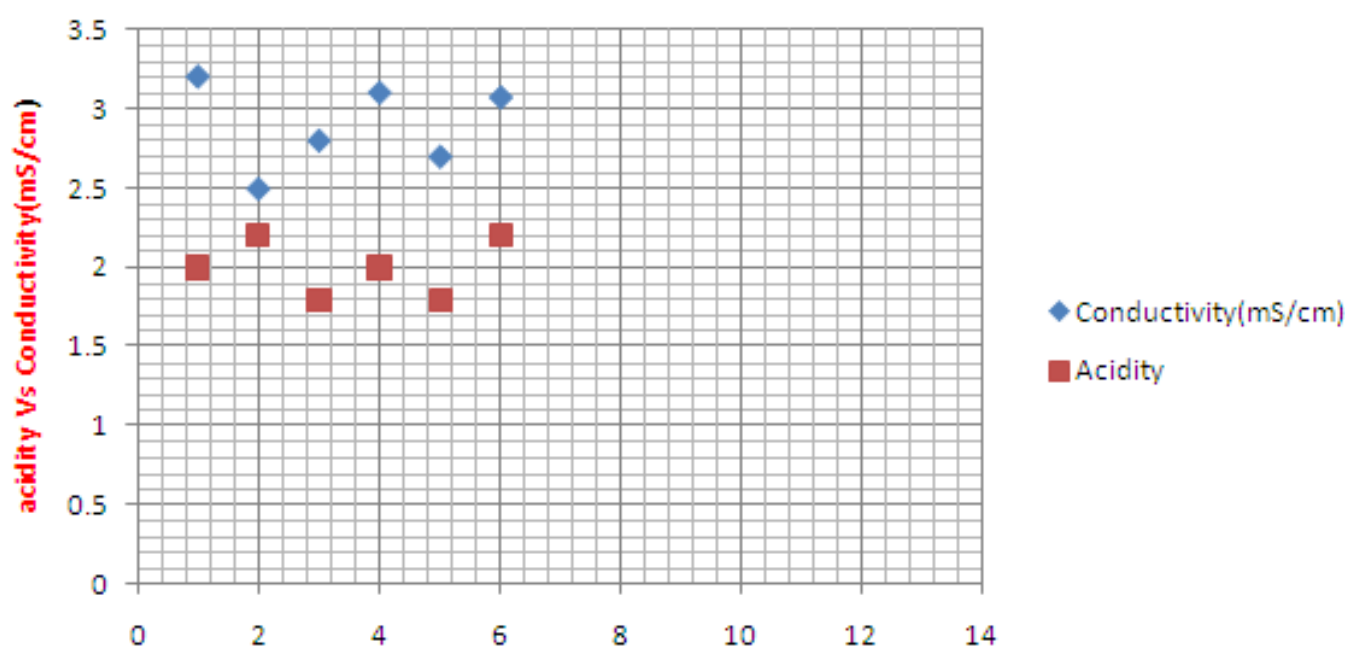

Figure 3. conductivity versus acidity in winter honey

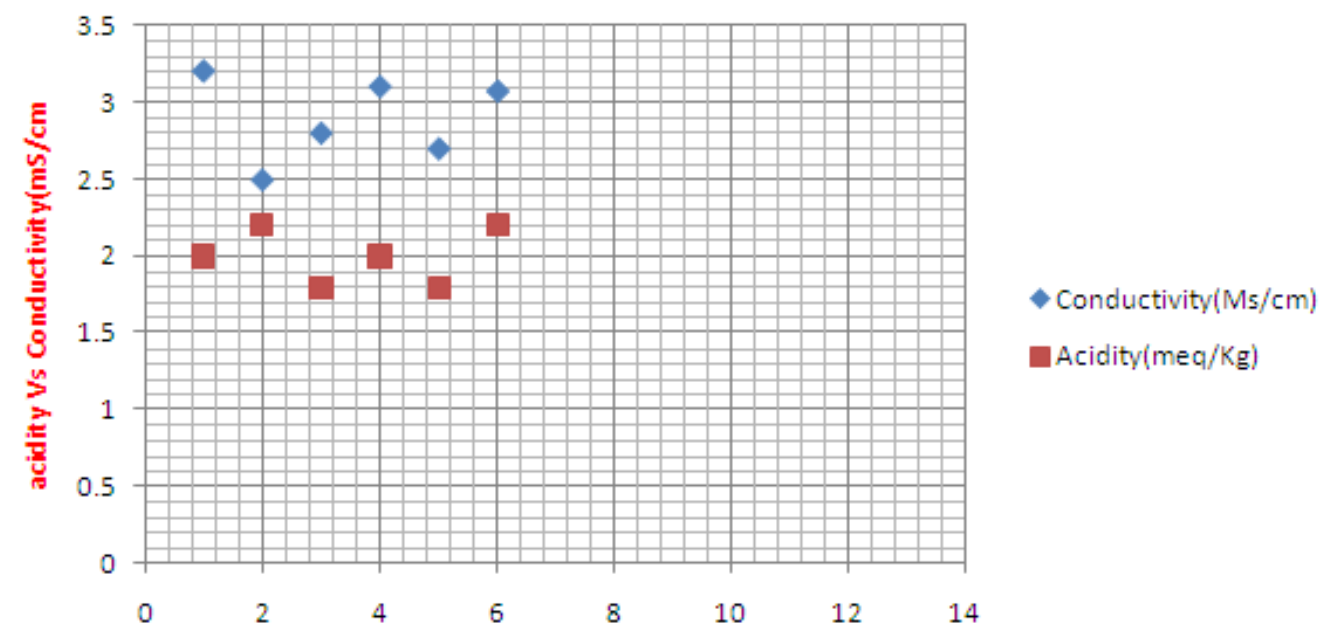

Figure 4. conductivity versus acidity of winter honey

\section{Conclusions}

The conductivity of honey samples collected from different sites of the same district during summer season has been analyzed at $20^{\circ} \mathrm{C} \pm 0.5$. According to the work the conductivity of darker honey detected to be greater than the lighter honey. The conductivity in summer season is compared with winter season and the results become almost fall in similar range since the honey product detected was floral and no more components is significantly added with season change. Furthermore the conductivity detected is fair and fit with international honey commission standards. The 
acidity of honey samples has been determined and almost darker honey exhibited slightly high acidity.

\section{Acknowledgements}

First of all I would like to express my heart full appreciation to almighty God. Secondly to Mizan Tepi University in accessing the instrumentation and chemicals and lastly to Mr Guta Amenu (Lab. assistant)

\section{REFERENCES}

[1] Urska Kropf, Mojca Jamnik, Jasna Bertoncelj and Terezija Golob (2007). Linear Regression Model of the Ash Mass Fraction and Electrical Conductivity for Slovenian Honey, Slovenia

[2] Carolina Acquarone, Pilar Buera, Beatriz Elizalde (2002). Pattern of $\mathrm{pH}$ and electrical conductivity upon honey dilution as a complementary tool for discriminating geographical origin of honeys. Argentina

[3] http://www.bee-hexagon.net/en/network.htm (2001) Harmonized methods of the international honey commission. Athens

[4] Pridal1, 1. Vorlova. 2002(10). Honey and its physical parameters Czech J. Anim. Sci., 47, 439-444 Czech
Republic.

[5] Mojca Jamnik, Jasna Bertoncelj and Terezija Golob (2008). Linear Regression Model of the Ash Mass Fraction and Electrical Conductivity for Slovenian Honey Food Technol. Biotechnology. (3) 335-340, Slovenia.

[6] Pourtallier, Y, Taliercio (1972). Honey control analyses Apiacta 1, France.

[7] Stefan Bogdanov (2001). Harmonized methods of the international honey commission World network of honey science, Greece

[8] Assoc. Public Analysts (1992). / MAFF validated method for acidity in honey (4) 171-175.

[9] Stefan Bogdanov (2000): Review of the work of international honey commission

[10] W.R., Junk and H.M., Pancoast - Handbook of sugars. Avi Publ. Co. Inc., Westport, Connecticut, USA: (1973); pp.295-296;

[11] M. Battaglini and G.Bosi - Caratterizzazione chimicofisica dei mieli monoflora sulla base dell spettro glucidicoe del potere rotatorio specifico. - Scienzae tecnologia degli Alimenti, (4): (217- 221) (1973).

[12] Codex Alimentarius standard for honey, Ref.Nr.CL 1993/14SH- FAO and WHO, Rome 1993

[13] Bogdanov S., Martin P. and Lullmann C. Harmonized methods of European honey commission, Apidologie(extra issue) (1997) pp1-59. 